\title{
Endocannabinoids and Endovanilloids: A Possible Balance in the Regulation of the Testicular GnRH Signalling
}

\author{
Rosanna Chianese, ${ }^{1}$ Vincenza Ciaramella, ${ }^{1}$ Donatella Scarpa, ${ }^{1}$ Silvia Fasano, ${ }^{1}$ \\ Riccardo Pierantoni, ${ }^{1}$ and Rosaria Meccariello ${ }^{2}$ \\ ${ }^{1}$ Dipartimento di Medicina Sperimentale Sezione "F. Bottazzi," Seconda Università di Napoli, \\ Via Costantinopoli 16, 80138 Napoli, Italy \\ ${ }^{2}$ Dipartimento di Scienze Motorie e del Benessere, Università di Napoli Parthenope, Via Medina 40, \\ 80133 Napoli, Italy
}

Correspondence should be addressed to Riccardo Pierantoni; riccardo.pierantoni@unina2.it

Received 8 July 2013; Accepted 30 July 2013

Academic Editor: Natalia Battista

Copyright (C) 2013 Rosanna Chianese et al. This is an open access article distributed under the Creative Commons Attribution License, which permits unrestricted use, distribution, and reproduction in any medium, provided the original work is properly cited.

Reproductive functions are regulated both at central (brain) and gonadal levels. In this respect, the endocannabinoid system (eCS) has a very influential role. Interestingly, the characterization of eCS has taken many advantages from the usage of animal models different from mammals. Therefore, this review is oriented to summarize the main pieces of evidence regarding eCS coming from the anuran amphibian Rana esculenta, with particular interest to the morphofunctional relationship between eCS and gonadotropin releasing hormone $(\mathrm{GnRH})$. Furthermore, a novel role for endovanilloids in the regulation of a testicular GnRH system will be also discussed.

\section{Introduction}

Endocannabinoids (eCBs) - such as anandamide (AEA) and 2-arachidonoylglycerol (2-AG)-are lipophilic molecules that work as integral part of the endocannabinoid system (eCS), mimicking several actions of $\Delta^{9}$-tetrahydrocannabinol (THC), the active principle of Cannabis sativa. Although the existence of an intracellular receptor has been suspected, eCBs exert their actions by binding to specific membrane receptors, $\mathrm{CB} 1$ and $\mathrm{CB} 2[1,2]$, whose expression is widespread in all species analyzed to date [3]. Unlike 2-AG, AEA also binds to the intracellular site of the type-1 vanilloid receptor (TRPV1), a cation channel receptor also activated by the pungent compound of hot chili pepper, and capsaicin (CAP, 8-methyl- $N$-vanillyl-6-nonenamide) [4]. Other receptors such as GPR55 and GPR119 have been considered putative cannabinoid receptors, however with some hesitation [5].

Although eCBs are lipidic compounds able to traverse plasma membrane by passive diffusion, the existence of a hypothetical eCB transporter has been suggested. In this respect, AEA intracellular carriers belonging to fatty acid binding proteins (FABP) family have been discovered [8]. In addition, eCBs can be also inactivated by a mechanism of cellular reuptake followed by an intracellular degradation mediated by fatty acid amide hydrolase (FAAH) [9] and monoacylglycerol lipase (MAGL) [10]. In neurons, a cytosolic variant of FAAH-1, termed FLAT-which lacks amidase activity but binds AEA with low micromolar affinity—has been considered as an AEA transporter [11]. Endocannabinoid system also includes several enzymes responsible for endocannabinoid biosynthesis such as $N$-acylphosphatidylethanolamine(NAPE-)specific phospholipase-D (PLD) for AEA [12] and sn-1-diacylglycerol lipase (DAGL) for 2-AG [13].

During the course of the years, the eCS has been characterized and studied from a functional point of view in many species [14-17]. In this regard, the use of nonmammalian animal models has contributed to a better comprehension about the eCS actions, especially in several reproductive events [16, 18-20]. In fact, nonmammalian vertebrates offer a broad spectrum of potentialities, besides, to allow evolutionary speculations. Most of them are seasonal breeders; therefore temperature and photoperiod-easily adjustable in 
laboratory-deeply control their gonadal activity. In addition, both brain and gonad architecture show morphological features simpler than mammals thus to easily study relationships between different neuroendocrine/paracrine systems [21].

\section{Rana esculenta: An Experimental Model to Study the eCS at Both Central and Testicular Levels}

The choice of an appropriate animal model is a basic step in the configuration of an experimental approach. Very often the difficulties found in the determination of molecular mechanisms on the basis of important physiological functionswhen studied in mammals-incite to select other animal models, especially nonmammalian vertebrates. With this in mind, the anuran amphibian Rana esculenta has been a suitable model for the comprehension of endocannabinoid role in reproduction at both central and testicular levels.

During the annual cycle of this seasonal breeder, the gonadotropin-releasing hormone $(\mathrm{GnRH})$ - the main regulator of gonadal activity-accumulates in the brain in the postreproductive period and is slowly released during the winter stasis to sustain the gonadotropin discharge in order to assess the beginning of a new reproductive wave [2224]. Furthermore, this amphibian shows a laminated type brain-an archetype of those more elaborated of the higher vertebrates-in which GnRH secreting neurons occupy wellknown and distinct areas, differently from mammals in which they are quite scattered in the brain [25]. Additionally, frog spermatogenesis proceeds slowly, orchestrated by environmental factors, testicular mediators, and hormonal milieu characterized by cyclic fluctuations. In particular, in specific periods of the annual sexual cycle it is possible to identify in testis a defined and well-known population of germ cells thanks to a very peculiar cystic organization. This consists in Sertoli cells enveloping clusters of germ cells at a synchronous stage $[26,27]$.

The characterization of eCS in R. esculenta begun in 2006 with the molecular cloning and the expression analysis of $c b 1[28,29]$. As indicated above, endocannabinoid activity requires multiple receptors, and this issue is stressed by the discovery of duplicated genes in fish [30,31], by the detection of several cannabinoid receptor splicing forms [32-34] as well as by the discussed existence of receptors other than CB1/CB2 [5]. In frog, the characterization of $c b 1$ did not revealed any splicing form but nucleotide differences among brain/testis CDNA and genomic sequences together with the corresponding amino acidic variations $[18,19,29]$ as a consequence of a possible editing process. Such a phenomenon seems to occur in other vertebrates and to affect RNA folding, stability and turnover. However, at present, synonymous and nonsynonymous mutations in $c b 1 / c b 2$ and Faah genes have been reported in humans and have been linked to several diseases such as metabolic and reproductive disorders, feeding behaviour, obesity, and schizophrenia [35-40].

In amphibian brain, CB1 is widely distributed in the forebrain $[41,42]$, the encephalic area mainly involved in the control of reproductive functions, being primarily responsible for the biosynthesis of GnRH [21]. As deeply described in the next paragraph, functional crosstalk between eCBs and GnRH system emerged in frog.

As in other vertebrates and in the central nervous system, $c b 1$ is widely expressed in frog tissues, gonads included [28]. Fluctuations of $c b 1$ expression have been reported in both testis and brain during the annual sexual cycle [28] with testicular CB1 mRNA/protein $[6,7,28]$ detected in parallel to FAAH in germ cells, especially in elongated spermatids and spermatozoa as observed in other vertebrates (Figures 1(a) and $1(b))[6,7,42-49]$ and in sea urchin as well [50].

In rodents and in germ cells, CB1 has also been detected in Leydig cells suggesting its possible involvement in Leydig cell ontogenesis and steroidogenetic activity [51-53]; interestingly, in frog $c b 1$ mRNA was only observed in interstitial compartment (Figures 1(b) and 1(c)), and its expression profile well correlates with seasonal testosterone production [54]. Together with the ability to degrade AEA, frog testis might be able to produce eCBs during the annual reproductive cycle as suggested by Nape-pld expression and localization [6]. In the germinal compartment Nape-pld mRNA has been observed in secondary spermatogonia and spermatocytes cysts as well as in Sertoli cells surrounding primary spermatogonia; the strongest signal has been found in the interstitium throughout the annual sexual cycle (Figures 1(d)-1(f)).

Taken all together, data in frog clearly confirm a deep evolutionarily conserved involvement of eCBs in germ cell progression and sperm cell functions [43-49, 55-57]. Accordingly, as in human, boar, bull, rodents, and sea urchin, also in frog AEA modulates sperm motility [7, 43, 49, 50, 58, 59], indicating an evolutionarily conserved role in the regulation of such a reproductive function.

\section{Relationship between eCS and GnRH System}

The presence of $c b 1$ in frog brain, mainly in the forebrain and midbrain - as also observed from fish to mammals [14, $41,60,61]$-has suggested that eCS is able to control reproductive functions through a central regulation. This is in line with the discovery that hypothalamic immortalized GnRH secreting neurons possess a complete eCS, CB1 included [62] and that AEA inhibits $\mathrm{GnRH}$ release from rat mediobasal hypothalamus [63]. During the annual sexual cycle, $c b 1$ mRNA fluctuations are opposite as compared to GnRH-1 $[19,42]$; in particular, in frog diencephalons-the encephalic area mainly involved in the release of $\mathrm{GnRH}-c b 1$ expression shows a peak in December, when low levels of GnRH have been detected $[22,24,64]$. The total CB1 protein content has also been assayed in frog forebrain, midbrain, and hindbrain $[16,19]$ during the year; intriguingly, $\mathrm{GnRH}$ release correlates with the minimal levels of CB1 detected in both telencephalon and diencephalon. Accordingly, neuroanatomical and functional relationships between $\mathrm{CB} 1$ and $\mathrm{GnRH}$ have been discovered in R. esculenta brain by immunofluorescence; in particular, CB1 has been found in a subpopulation of the septal and preoptic GnRH-1 neurons [42]. In addition, the in vitro treatment of frog diencephalons with AEA has an inhibitory 
$c b 1$

November

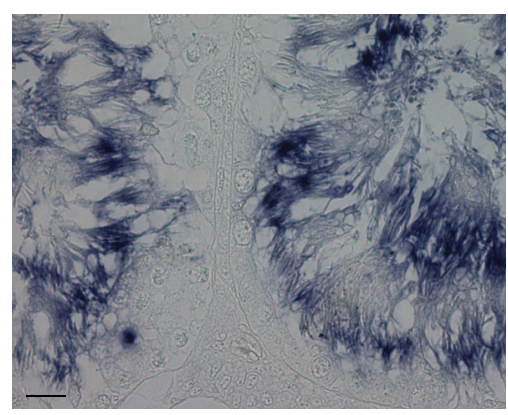

(a)

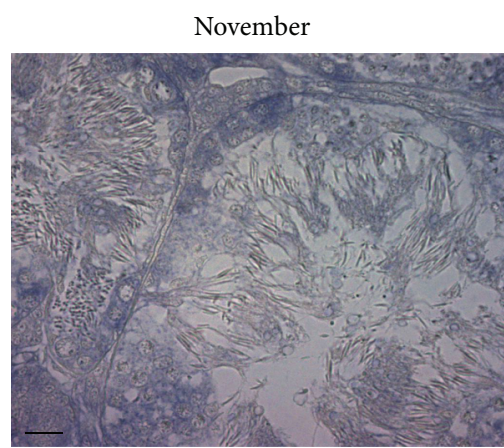

(d)
February

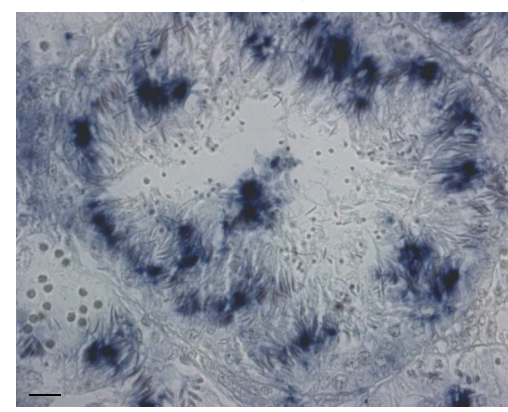

(b)

Nape-pld



(e)
June

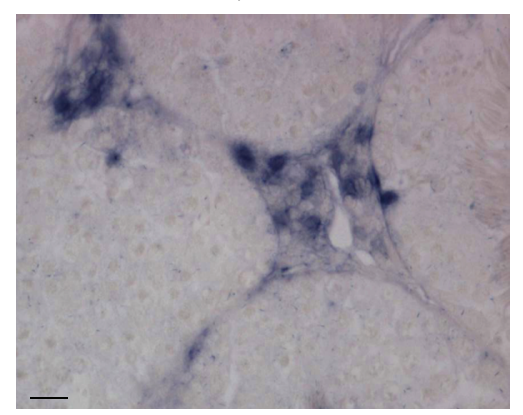

(c)

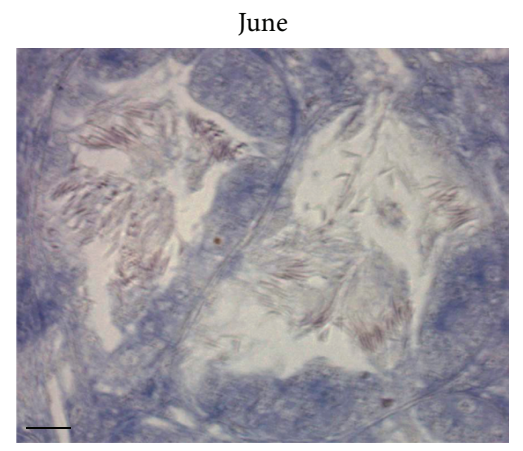

(f)

FIgURE 1: Localization of $c b 1$ and Nape-pld mRNA in the frog testis evaluated by in situ hybridization in November (a) and (d), February (b) and (e), and June (c) and (f). Scale bar: $20 \mu \mathrm{m}$.

effect upon GnRH-1 expression, via cb1 activation [42]. Such a functional crosstalk between the eCS and GnRH is really more complicated, due to the existence of multiple $\mathrm{GnRH}$ and gonadotropin-releasing hormone receptor (GnRH-R) molecular forms in R. esculenta. In particular, in frog diencephalons, AEA, with a fine CB1-dependent regulation, is able to decrease $G n R H-1$ and $G n R H-2$ and increase $G n R H-R 1$ and GnRH-R2 expression, with no effect upon GnRH-R3 [65].

In the last years an emerging idea is that the inhibitory action of eCBs on reproductive functions, especially on GnRH neurons activity, might be pondered by new molecules positively affecting reproduction, such as the kisspeptins [66]. Interestingly, the kisspeptin receptor, GPR54, has been cloned and characterized in frog [67], and AEA, in vivo, inhibits the hypothalamic GnRH system via GPR54 [Chianese et al., unpublished results].

In the wake of brain analysis, a deep characterization of GnRH system in relation to eCS has been carried out in frog testis as well [6] (Figure 2). CB1 protein peaks have been observed in periods of the cycle characterized by massive formations of postmeiotic cells (September) and during the breeding season (March) with CB1 mainly localized in postmeiotic stages. Interestingly, the expression profiles of testicular GnRHs clearly indicate their increase in postreproductive period, with $G n R H-1$ increased expression occurring from May to July and GnRH-2 expression presenting a single expression spike in June [6]. Thus, in a period in which both $\mathrm{CB1}$ and FAAH proteins are scantly expresseds GnRH is overexpressed (Figure 2).

GnRH works as a testicular bioregulator affecting spermatogenesis, sperm release, and fertilization [21, 68, 69], processes also driven by eCBs. With this in mind, we carried out in vitro incubations of frog testis with AEA choosing two periods of the annual cycle: June (postreproductive period), when testis is reach in meiotic stages; February (end of the winter stasis), when the upsurge of a new spermatogenetic wave occurs. Intriguingly, frog testis shows a quite different modulation of the GnRH system by AEA in comparison to brain. In fact, in frog diencephalon GnRH-1 and GnRH2-both hypophysiotropic factors [21] - are localized in the anterior preoptic area, and their transcripts are both inhibited by AEA, whereas in testis they are differently expressed, probably working in different reproductive events. In particular, in June, when spermatogenesis slightly proceeds, an opposite regulation by AEA has been observed since AEA decreases $G n R H-1$ and increases $G n R H-2$ expression (Figures 3(a) and 3(c)), through $c b 1$ activation (Figure 4(a)) [6]. Furthermore, a specific modulation by AEA has also been observed on GnRH-Rs expression, since AEA upregulates $G n R H-R 1$ and decreases $G n R H-R 2$ expression, without any effect upon GnRH-R3 (Figures 4(a), 4(c), and 4(e)). Interestingly, in February, when testis simply contains quiescent spermatogonia and spermatozoa attached to Sertoli cells, AEA affects $G n R H-2$ and $G n R H-R 2$, a system supposed to 


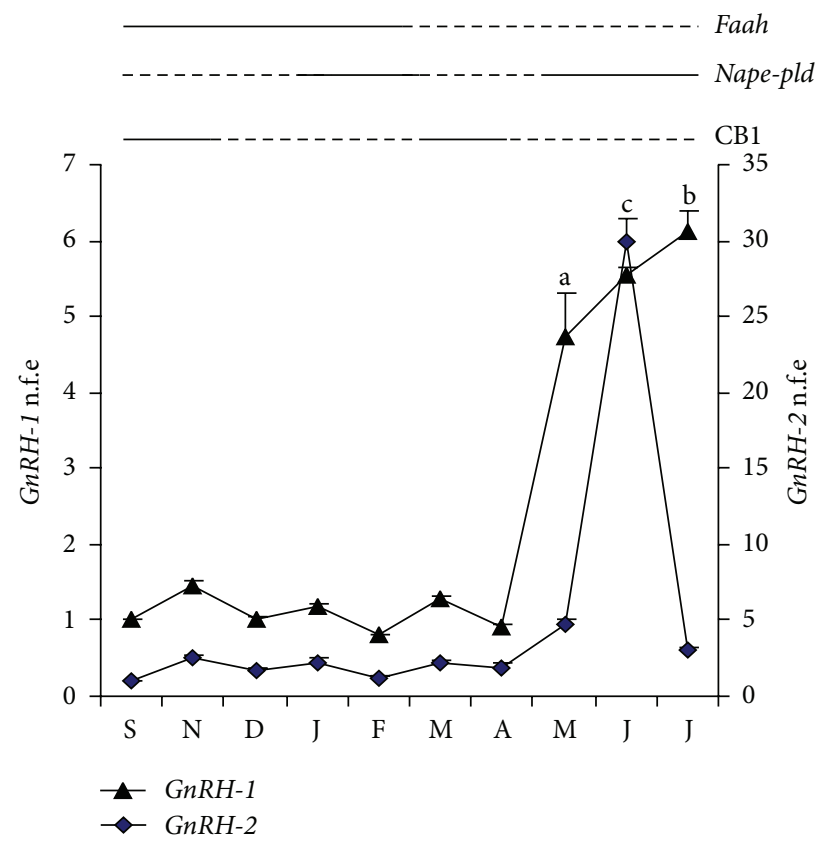

Figure 2: Analysis of GnRH1, GnRH-2, and some molecular components of the endocannabinoid system in frog testis during the annual sexual cycle. For GnRH-1, GnRH-2, and Nape-pld mRNA data from [6]; for FAAH and CB1 protein data from [7]. Dotted lines: low levels; black lines: high levels. n.f.e.= normalized fold expression. Different letters indicate statistically significant differences.



(a)



(c)

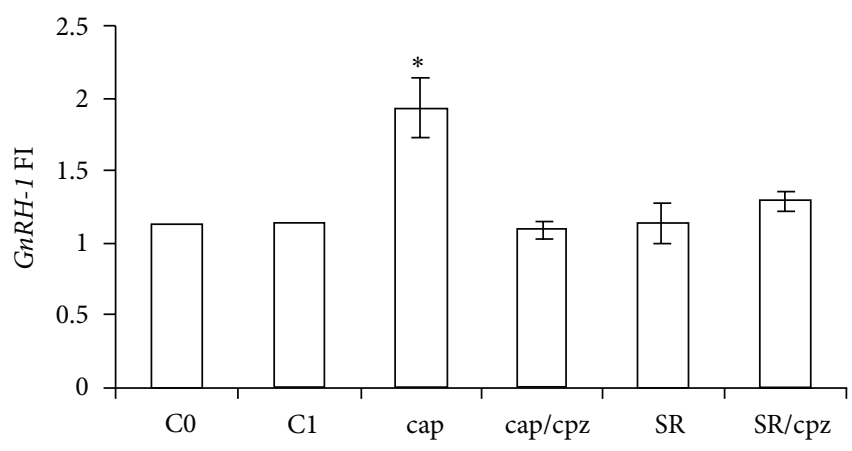

(b)

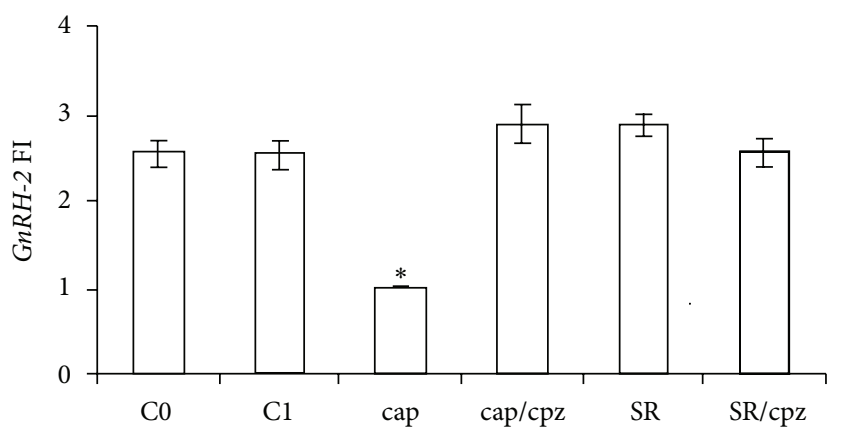

(d)

FiguRE 3: Effects of AEA treatment on GnRH-1 (a) and GnRH-2 (c) expression in frog testis collected from June animals ( $N=5 /$ group) after $1 \mathrm{~h}$ of incubation. Incubations have been carried out with AEA $10^{-9} \mathrm{M}, \mathrm{SR} 10^{-8} \mathrm{M}$, or both. C0: untreated testis of June; C: control group, testis treated with Krebs-Ringer buffer. Effects of cap treatment on GnRH-1 (b) and GnRH-2 (d) expressions in frog testis of June after $1 \mathrm{~h}$ of incubation. Incubations have been carried out with cap $10^{-6} \mathrm{M}, \mathrm{cpz} 10^{-5} \mathrm{M}, \mathrm{SR} 10^{-8} \mathrm{M}$, or combinations of cap/cpz and SR/cpz. C0: untreated testis of June; C1: control group, testis treated with Krebs-Ringer buffer. The data in graph are the results of RT-PCR analysis; they are reported as fold increase (FI) calculated comparing the expression of $G n R H-1 / G n R H-2$ to the housekeeping $f p 1$ and are representative of three separate experiments at least $(N=6)$. Asterisks indicate statistically significant differences. 


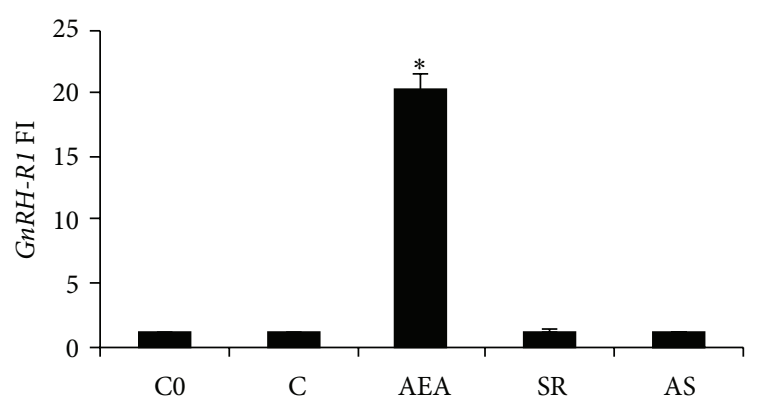

(a)

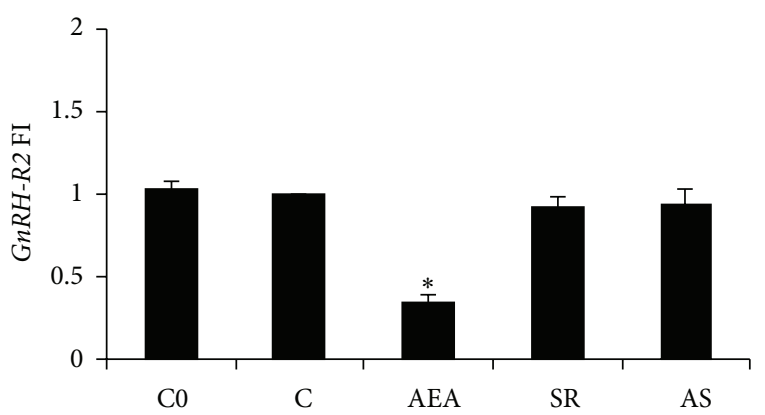

(c)

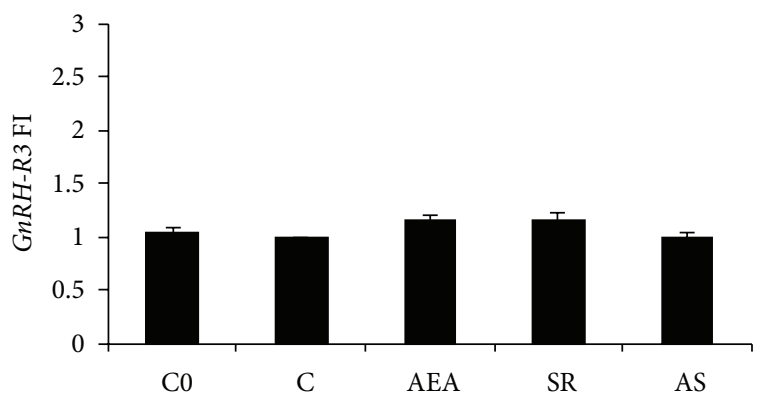

(e)

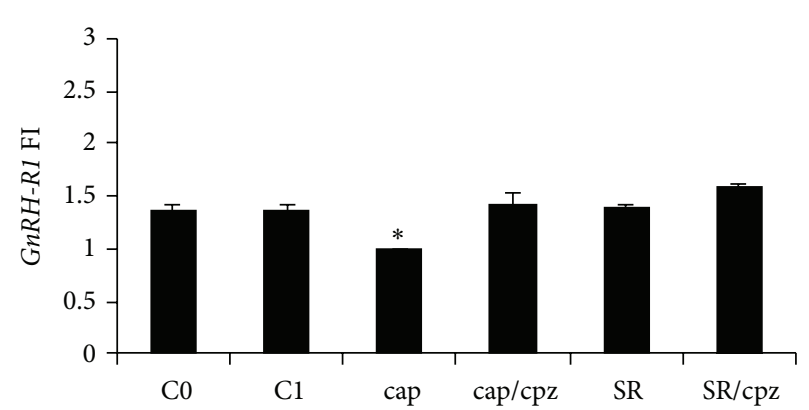

(b)

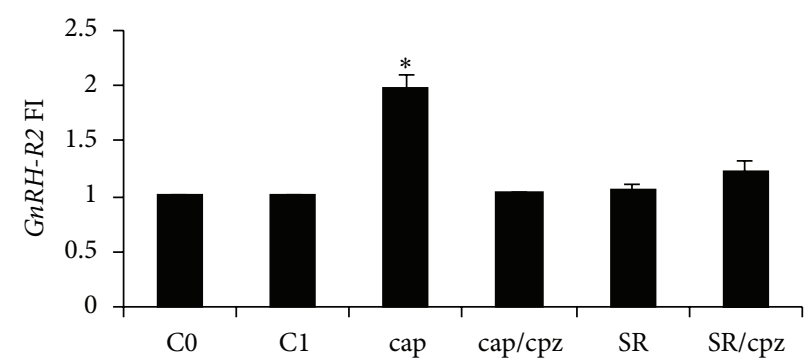

(d)

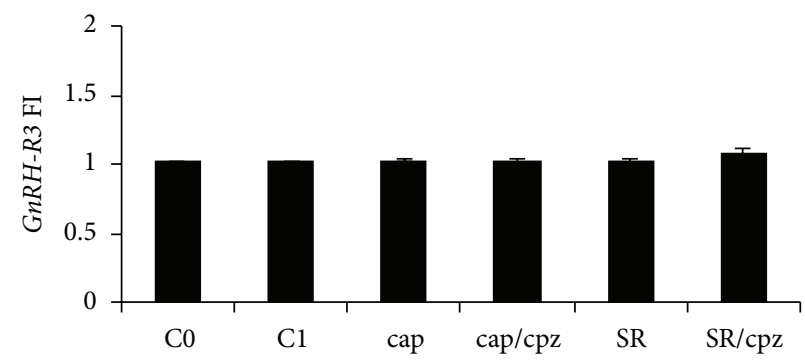

(f)

Figure 4: Effects of AEA treatment on GnRH-R1 (a), GnRH-R2 (c), and GnRH-R3 (e) expressions in frog testis collected from June animals $\left(N=5\right.$ /group) after $1 \mathrm{~h}$ of incubation. Incubations have been carried out with AEA $10^{-9} \mathrm{M}, \mathrm{SR} 10^{-8} \mathrm{M}$, or both. C0: untreated testis of June; C: control group, testis treated with Krebs-Ringer buffer. Effects of cap treatment on GnRH-R1 (b), GnRH-R2 (d), and GnRH-R3 (f) expressions in frog testis of June after $1 \mathrm{~h}$ of incubation. Incubations have been carried out with cap $10^{-6} \mathrm{M}, \mathrm{cpz} 10^{-5} \mathrm{M}$, SR $10^{-8} \mathrm{M}$, or combinations of cap/cpz and SR/cpz. C0: untreated testis of June; C1: control group, testis treated with Krebs-Ringer buffer. The data in graph are the results of RT-PCR analysis; they are reported as fold increase (FI) calculated comparing the expression of $G n R H$-Rs to the housekeeping $f p 1$ and are representative of three separate experiments at least $(N=6)$. Asterisks indicate statistically significant differences.

be involved in Sertoli-spermatozoa communication, and does not modulate $G n R H-1 / G n R H-R 1$, a system supposed to be involved in germ cell progression [6]. Therefore, AEA might modulate testicular GnRH signalling at multiple levels and in a stage dependent manner [6].

\section{Relationship between Endovanilloids and GnRH System}

As mentioned above, AEA has a dual potentiality thanks to the ability to bind to both CB1 and TRPV1 and so working as an endocannabinoid and an endovanilloid as well. In the context of reproduction, this peculiarity makes AEA a dual regulator of acrosome reaction (AR). In boar sperm, AEApresent in both seminal plasma and uterine fluids-prevents, via CB1, premature capacitation and inhibits AR [43]. By contrast, a few hours later, when sperm have reached the oviduct, this inhibitory brake becomes less stringent, since AEA concentration progressively reduces. At this time, AEA works as endovanilloid activating TRPV1 [43]. Such an activation prevents spontaneous $\mathrm{AR}$, an uncontrolled phenomenon of exocytosis that leads quickly to cell death [70]. Besides functions related to fertilizing ability due to intracellular AEA signalling, few and contradictory studies have analyzed the effects of CAP, the agonist of TRPV1, in male germ cell progression. In the past, CAP, acting as specific neurotoxin that irreversibly caused degeneration of sensory $\mathrm{C}$ fibres of the peripheral nerves, was investigated for its ability to affect testicular descent [71]. However, CAP has been reported to adversely affects the survival of rat spermatogonial cell lines 


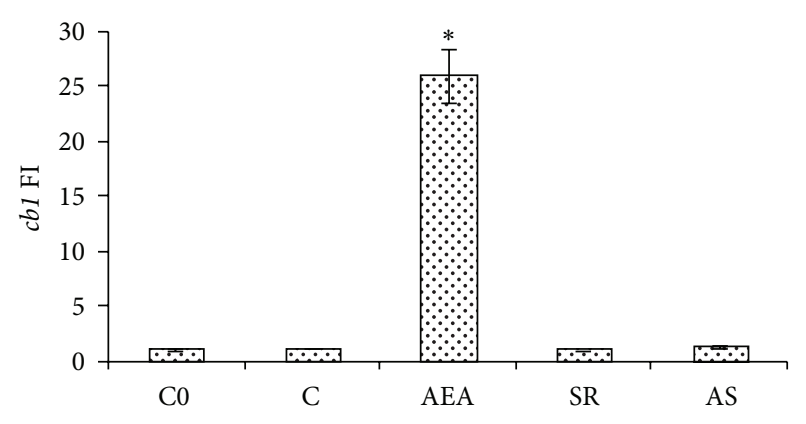

(a)

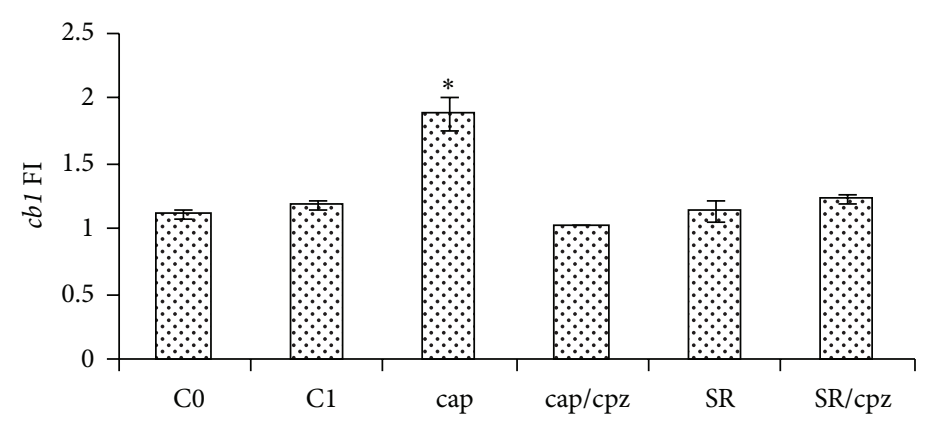

(b)

Figure 5: Effects of AEA treatment on $c b 1$ (a) expression in frog testis collected from June animals $(N=5 /$ group $)$ after $1 \mathrm{~h}$ of incubation. Incubations have been carried out with AEA $10^{-9} \mathrm{M}, \mathrm{SR} 10^{-8} \mathrm{M}$, or both. C0: untreated testis of June; C: control group, testis treated with Krebs-Ringer buffer. Effects of cap treatment on $c b 1$ (b) expression in frog testis of June after $1 \mathrm{~h}$ of incubation. Incubations have been carried out with cap $10^{-6} \mathrm{M}, \mathrm{cpz} 10^{-5} \mathrm{M}$, SR $10^{-8} \mathrm{M}$, or combinations of cap/cpz and SR/cpz. C0: untreated testis of June; C1: control group, testis treated with Krebs-Ringer buffer. The data in graph are the results of RT-PCR analysis; they are reported as fold increase (FI) calculated comparing the expression of $c b 1$ to the housekeeping $f p 1$ and are representative of three separate experiments at least $(N=6)$. Asterisks indicate statistically significant differences.

expressing TRPV1 [72], whereas a protective role against heat stress has been suggested for TRPV1 [73]. Conversely in mouse, a diet containing $0.02 \%$ CAP enhances testicular cell proliferation and affects the release of both testosterone and ghrelin, the latter being an acylated polypeptide hormone mainly secreted by the endocrine cells of the stomach [74]. Interestingly, in mammals, TRPV1 is expressed in Sertoli cells [75] and germ cells, with high levels of both mRNA and protein detected from spermatocytes to spermatids stages [55]. At present, none has investigated a possible role of endovanilloids in GnRH signalling, either at central level or at testicular level. Once again a simple animal model as $R$. esculenta has shed light on such a mechanism. In parallel to AEA treatment of frog testis, in June, in vitro stimulation with CAP has been carried out. Interestingly, the effects observed upon GnRH system have been opposite to those of AEA. In particular, CAP increases $G n R H-1$ and decreases $G n R H-2$ (Figure 3); then, it decreases $G n R H-R 1$ and increases $G n R H$ $R 2$, with no effect on GnRH-R3 (Figure 4). These effects have been completely counteracted by capsazepine (CPZ), a competitive TRPV1 antagonist [76]. No effects have been observed after SR141716A (SR), a CB1 antagonist, alone or in combination with CPZ. Interestingly, CAP affects $c b 1$ expression as well (Figure 5) suggesting a possible overlapping between the eCB and the endovanilloid system.

\section{Closing Remarks}

The eCS field is an important example of the kinds of inputs that studies of comparative endocrinology can give to our knowledge. The contribution of lower vertebrate animal models in reproduction research is very strong not only because they make easy the investigation of mechanisms regulating mammalian reproductive physiology but also because they allow to understanding on how these mechanisms have evolved.

The frog R. esculenta has been a suitable model for a complete characterization of the eCS. Thanks to its feature as seasonal breeder, $G n R H$ and $c b 1$ expression profiles have been compared indicating the existence of a physiological reverse relationship between the two systems. More interestingly what happens in brain not always can be confirmed in testis; in fact, a different regulation by AEA of the GnRH system has emerged in frog brain and testis. In addition, a novel role can be ascribed to endovanilloids as new regulators of the $\mathrm{GnRH}$ system in testis. Furthermore, it is reasonable that eCBs and endovanilloids might work as two different faces of the same medal since an opposite regulation of each component of the GnRH system by these molecules has been described.

\section{Acknowledgments}

This work was supported by PRIN 2010/2011 to Rosaria Meccariello. This work is dedicated to the memory of Maria Fosca Franzoni (Università degli Studi di Torino, Italy) for her outstanding contributions to comparative endocrinology.

\section{References}

[1] L. A. Matsuda, S. J. Lolait, M. J. Brownstein, A. C. Young, and T. I. Bonner, "Structure of a cannabinoid receptor and functional expression of the cloned cDNA," Nature, vol. 346, no. 6284, pp. 561-564, 1990.

[2] S. Munro, K. L. Thomas, and M. Abu-Shaar, "Molecular characterization of a peripheral receptor for cannabinoids," Nature, vol. 365, no. 6441, pp. 61-65, 1993.

[3] K. Mackie, "Cannabinoid receptors: where they are and what they do," Journal of Neuroendocrinology, vol. 20, no. 1, pp. 10-14, 2008.

[4] M. van der Stelt and V. di Marzo, "Anandamide as an intracellular messenger regulating ion channel activity," Prostaglandins and other Lipid Mediators, vol. 77, no. 1-4, pp. 111-122, 2005.

[5] A. J. Brown, "Novel cannabinoid receptors," British Journal of Pharmacology, vol. 152, no. 5, pp. 567-575, 2007.

[6] R. Chianese, V. Ciaramella, D. Scarpa, S. Fasano, R. Pierantoni, and R. Meccariello, "Anandamide regulates the expression of GnRH1, GnRH2, and GnRH-Rs in frog testis," American Journal 
of Physiology Endocrinology Metabolism, vol. 303, no. 4, pp. E475-E487, 2012.

[7] G. Cobellis, G. Cacciola, D. Scarpa et al., "Endocannabinoid system in frog and rodent testis: type-1 cannabinoid receptor and fatty acid amide hydrolase activity in male germ cells," Biology of Reproduction, vol. 75, no. 1, pp. 82-89, 2006.

[8] M. Kaczocha, S. T. Glaser, and D. G. Deutsch, "Identification of intracellular carriers for the endocannabinoid anandamide," Proceedings of the National Academy of Sciences of the United States of America, vol. 106, no. 15, pp. 6375-6380, 2009.

[9] B. F. Cravatt, D. K. Giang, S. P. Mayfield, D. L. Boger, R. A. Lerner, and N. B. Gilula, "Molecular characterization of an enzyme that degrades neuromodulatory fatty-acid amides," Nature, vol. 384, no. 6604, pp. 83-87, 1996.

[10] T. P. Dinh, T. F. Freund, and D. Piomelli, "A role for monoglyceride lipase in 2-arachidonoylglycerol inactivation," Chemistry and Physics of Lipids, vol. 121, no. 1-2, pp. 149-158, 2002.

[11] J. Fu, G. Bottegoni, O. Sasso et al., "A catalytically silent FAAH-1 variant drives anandamide transport in neurons," Nature Neuroscience, vol. 15, no. 1, pp. 64-69, 2012.

[12] Y. Okamoto, J. Morishita, K. Tsuboi, T. Tonai, and N. Ueda, "Molecular characterization of phospholipase D generating anandamide and its congeners," The Journal of Biological Chemistry, vol. 279, no. 7, pp. 5298-5305, 2004.

[13] N. Stella, P. Schweitzer, and D. Plomelli, "A second endogenous' cannabinoid that modulates long-term potentiation," Nature, vol. 388, no. 6644, pp. 773-778, 1997.

[14] E. Cottone, A. Guastalla, K. Mackie, and M. F. Franzoni, "Endocannabi-noids affect the reproductive functions in teleosts and amphibians," Molecular and Cellular Endocrinology, vol. 286, no. 1-2, supplement 1, pp. S41-S45, 2008.

[15] G. Cacciola, R. Chianese, T. Chioccarelli et al., "Cannabinoids and reproduction: a lasting and intriguing history," Pharmaceuticals, vol. 3, no. 10, pp. 3275-3323, 2010.

[16] R. Pierantoni, G. Cobellis, R. Meccariello et al., "CB1 activity in male reproduction: mammalian and nonmammalian animal models," Vitamins and Hormones, vol. 81, pp. 367-387, 2009.

[17] N. Battista, R. Meccariello, G. Cobellis et al., "The role of endocannabinoids in gonadal function and fertility along the evolutionary axis," Molecular and Cellular Endocrinology, vol. 355, no. 1, pp. 1-14, 2012.

[18] S. Fasano, R. Meccariello, G. Cobellis et al., "The endocannabinoid system: an ancient signaling involved in the control of male fertility," Annals of the New York Academy of Sciences, vol. 1163, pp. 112-124, 2009.

[19] R. Chianese, G. Cobellis, R. Pierantoni, S. Fasano, and R. Meccariello, "Non-mammalian vertebrate models and the endocannabinoid system: relationships with gonadotropin-releasing hormone," Molecular and Cellular Endocrinology, vol. 286, no. 1-2, supplement 1, pp. S46-S51, 2008.

[20] R. Chianese, T. Chioccarelli, G. Cacciola et al., "The contribution of lower vertebrate animal models in human reproduction research," General and Comparative Endocrinology, vol. 171, no. 1, pp. 17-27, 2011.

[21] R. Pierantoni, G. Cobellis, R. Meccariello, and S. Fasano, "Evolutionary aspects of cellular communication in the vertebrate hypothalamo-hypophysio-gonadal axis," International Review of Cytology, vol. 218, pp. 69-141, 2002.

[22] S. Fasano, H. J. Goos, C. Janssen, and R. Pierantoni, “Two GnRHs fluctuate in correlation with androgen levels in the male frog Rana esculenta," Journal of Experimental Zoology, vol. 266, no. 4, pp. 277-283, 1993.
[23] G. Cobellis, M. Vallarino, R. Meccariello et al., "Fos localization in cytosolic and nuclear compartments in neurones of the frog, Rana esculenta, brain: an analysis carried out in parallel with GnRH molecular forms," Journal of Neuroendocrinology, vol. 11, no. 9, pp. 725-735, 1999.

[24] R. Meccariello, M. Mathieu, G. Cobellis et al., "Jun localization in cytosolic and nuclear compartments in brain-pituitary system of the frog, Rana esculenta: an analysis carried out in parallel with GnRH molecular forms during the annual reproductive cycle," General and Comparative Endocrinology, vol. 135, no. 3, pp. 310-323, 2004.

[25] G. Chieffi, R. Pierantoni, and S. Fasano, "Immunoreactive GnRH in hypothalamic and extrahypothalamic areas," International Review of Cytology, vol. 127, pp. 1-55, 1991.

[26] R. K. Rastogi, L. Iela, P. K. Saxena, and G. Chieff, “The control of spermatogenesis in the green frog, Rana esculenta," Journal of Experimental Zoology, vol. 169, pp. 151-166, 1976.

[27] R. Pierantoni, G. Cobellis, R. Meccariello et al., "The amphibian testis as model to study germ cell progression during spermatogenesis," Comparative Biochemistry and Physiology B, vol. 132, no. 1, pp. 131-139, 2002.

[28] R. Meccariello, R. Chianese, G. Cacciola, G. Cobellis, R. Pierantoni, and S. Fasano, "Type-1 cannabinoid receptor expression in the frog, Rana esculenta, tissues: a possible involvement in the regulation of testicular activity," Molecular Reproduction and Development, vol. 73, no. 5, pp. 551-558, 2006.

[29] R. Meccariello, R. Chianese, G. Cobellis, R. Pierantoni, and S. Fasano, "Cloning of type 1 cannabinoid receptor in Rana esculenta reveals differences between genomic sequence and cDNA," FEBS Journal, vol. 274, no. 11, pp. 2909-2920, 2007.

[30] M. R. Elphick, "The evolution and comparative neurobiology of endocannabinoid signalling," Phylosophycal Transactions of the Royal Society Biological Science, vol. 367, no. 1607, pp. 3201-3215, 2012.

[31] E. Cottone, V. Pomatto, F. Cerri et al., "Cannabinoid receptors are widely expressed in goldfish: molecular cloning of a CB2like receptor and evaluation of $\mathrm{CB} 1$ and $\mathrm{CB} 2$ mRNA expression profiles in different organs," Fish Physiology and Biochemistry, 2013.

[32] E. Ryberg, H. K. Vu, N. Larsson et al., "Identification and characterisation of a novel splice variant of the human CB1 receptor," FEBS Letters, vol. 579, no. 1, pp. 259-264, 2005.

[33] Q.-R. Liu, C.-H. Pan, A. Hishimoto et al., "Species differences in cannabinoid receptor 2 (CNR2 gene): identification of novel human and rodent CB2 isoforms, differential tissue expression and regulation by cannabinoid receptor ligands," Genes, Brain and Behavior, vol. 8, no. 5, pp. 519-530, 2009.

[34] D. Shire, C. Carillon, M. Kaghad et al., "An amino-terminal variant of the central cannabinoid receptor resulting from alternative splicing," The Journal of Biological Chemistry, vol. 270, no. 8, pp. 3726-3731, 1995.

[35] J. Bienertova-Vasku, P. Bienert, Z. Dostalova, J. Chovanec, A. Vasku, and V. Vasku, "A common variation in the cannabinoid 1 receptor (CNR1) gene is associated with pre-eclampsia in the Central European population," European Journal of Obstetrics Gynecology and Reproductive Biology, vol. 155, no. 1, pp. 19-22, 2011.

[36] T. M. Baye, Y. Zhang, E. Smith et al., "Genetic variation in cannabinoid receptor 1 (CNR1) is associated with derangements in lipid homeostasis, independent of body mass index," Pharmacogenomics, vol. 9, no. 11, pp. 1647-1656, 2008. 
[37] A. L. Burgueño, S. Sookoian, T. F. Gianotti, C. Gemma, and C. J. Pirola, "Genetic variation in the FAAH gene and metabolic syndrome-related phenotypes," Obesity, vol. 17, no. 11, pp. 19791980, 2009.

[38] B. Ho, T. H. Wassink, S. Ziebell, and N. C. Andreasen, "Cannabinoid receptor 1 gene polymorphisms and marijuana misuse interactions on white matter and cognitive deficits in schizophrenia," Schizophrenia Research, vol. 128, no. 1-3, pp. 6675, 2011.

[39] A. G. Norrod and R. A. Puffenbenbarger, "Genetic polymorphisms of the endocannabinoid system," Chemistry and Biodiversity, vol. 4, no. 8, pp. 1926-1932, 2007.

[40] P. Monteleone, M. Bifulco, C. di Filippo et al., "Association of $\mathrm{CNR} 1$ and FAAH endocannabinoid gene polymorphisms with anorexia nervosa and bulimia nervosa: evidence for synergistic effects," Genes, Brain and Behavior, vol. 8, no. 7, pp. 728-732, 2009.

[41] E. Cottone, C. Salio, M. Conrath, and M. F. Franzoni, "Xenopus laevis CB1 cannabinoid receptor: molecular cloning and mRNA distribution in the central nervous system," Journal of Comparative Neurology, vol. 464, no. 4, pp. 487-496, 2003.

[42] R. Meccariello, M. F. Franzoni, R. Chianese et al., "Interplay between the endocannabinoid system and GnRH-I in the forebrain of the anuran amphibian Rana esculenta," Endocrinology, vol. 149, no. 5, pp. 2149-2158, 2008.

[43] M. Maccarrone, B. Barboni, A. Paradisi et al., "Characterization of the endocannabinoid system in boar spermatozoa and implications for sperm capacitation and acrosome reaction," Journal of Cell Science, vol. 118, no. 19, pp. 4393-4404, 2005.

[44] G. Ricci, G. Cacciola, L. Altucci et al., "Endocannabinoid control of sperm motility: the role of epididymus," General and Comparative Endocrinology, vol. 153, no. 1-3, pp. 320-322, 2007.

[45] M. Rossato, F. I. Popa, M. Ferigo, G. Clari, and C. Foresta, "Human sperm express cannabinoid receptor Cb1, the activation of which inhibits motility, acrosome reaction, and mitochondrial function," Journal of Clinical Endocrinology and Metabolism, vol. 90, no. 2, pp. 984-991, 2005.

[46] F. Francavilla, N. Battista, A. Barbonetti et al., "Characterization of the endocannabinoid system in human spermatozoa and involvement of transient receptor potential vanilloid 1 receptor in their fertilizing ability," Endocrinology, vol. 150, no. 10, pp. 4692-4700, 2009.

[47] A. Barbonetti, M. R. C. Vassallo, D. Fortunato, S. Francavilla, M. Maccarrone, and F. Francavilla, "Energetic metabolism and human sperm motility: impact of CB1 receptor activation," Endocrinology, vol. 151, no. 12, pp. 5882-5892, 2010.

[48] B. Barboni, N. Bernabò, P. Palestini et al., "Type-1 cannabinoid receptors reduce membrane fluidity of capacitated boar sperm by impairing their activation by bicarbonate," PLOS ONE, vol. 6, no. 8, Article ID e23038, 2011.

[49] G. Catanzaro, N. Battista, G. Rossi et al., "Effect of capacitation on the endocannabinoid system of mouse sperm," Molecular and Cellular Endocrinology, vol. 343, no. 1-2, pp. 88-92, 2011.

[50] H. Schuel, E. Goldstein, R. Mechoulam, A. M. Zimmerman, and S. Zimmerman, "Anandamide (arachidonylethanolamide), a brain cannabinoid receptor agonist, reduces sperm fertilizing capacity in sea urchins by inhibiting the acrosome reaction," Proceedings of the National Academy of Sciences of the United States of America, vol. 91, no. 16, pp. 7678-7682, 1994.

[51] G. Cacciola, T. Chioccarelli, K. Mackie et al., "Expression of type-1 cannabinoid receptor during rat postnatal testicular development: possible involvement in adult leydig cell differentiation," Biology of Reproduction, vol. 79, no. 4, pp. 758-765, 2008.

[52] M. C. Gye, H. H. Kang, and H. J. Kang, "Expression of cannabinoid receptor 1 in mouse testes," Archives of Andrology, vol. 51, no. 3, pp. 247-255, 2005.

[53] T. Wenger, C. Ledent, V. Csernus, and I. Gerendai, “The central cannabinoid receptor inactivation suppresses endocrine reproductive functions," Biochemical and Biophysical Research Communications, vol. 284, no. 2, pp. 363-368, 2001.

[54] M. D’Istria, G. Delrio, V. Botte, and G. Chieffi, "Radioimmunoassay of testosterone, 17beta-oestradiol and oestrone in the male and female plasma of plasma of Rana esculenta during sexual cycle," Steroids and Lipids Research, vol. 5, no. 1, pp. 42-48, 1974.

[55] P. Grimaldi, P. Orlando, S. di Siena et al., "The endocannabinoid system and pivotal role of the CB2 receptor in mouse spermatogenesis," Proceedings of the National Academy of Sciences of the United States of America, vol. 106, no. 27, pp. 11131-11136, 2009.

[56] G. Cobellis, G. Ricci, G. Cacciola et al., "A gradient of 2-arachidonoylglycerol regulates mouse epididymal sperm cell start-up," Biology of Reproduction, vol. 82, no. 2, pp. 451-458, 2010.

[57] T. Chioccarelli, G. Cacciola, L. Altucci et al., "Cannabinoid receptor 1 influences chromatin remodeling in mouse spermatids by affecting content of transition protein 2 mRNA and histone displacement," Endocrinology, vol. 151, no. 10, pp. 50175029, 2010.

[58] H. Schuel, L. J. Burkman, J. Lippes et al., "Evidence that anandamide-signaling regulates human sperm functions required for fertilization," Molecular Reproduction and Development, vol. 63, no. 3, pp. 376-387, 2002.

[59] M. G. Gervasi, C. Osycka-Salut, J. Caballero et al., "Anandamide capacitates bull spermatozoa through CB1 and TRPV1 activation," PLoS ONE, vol. 11, no. 6, Article ID e16993, 2011.

[60] E. Cottone, S. Forno, E. Campantico et al., "Expression and distribution of $\mathrm{CB} 1$ cannabinoid receptors in the central nervous system of the African cichlid fish Pelvicachromis pulcher," Journal of Comparative Neurology, vol. 485, no. 4, pp. 293-303, 2005.

[61] L. A. Matsuda, T. I. Bonner, and S. J. Lolait, "Localization of cannabinoid receptor mRNA in rat brain," Journal of Comparative Neurology, vol. 327, no. 4, pp. 535-550, 1993.

[62] C. M. Gammon, G. M. Freeman Jr., W. Xie, S. L. Petersen, and W. C. Wetsel, "Regulation of gonadotropin-releasing hormone secretion by cannabinoids," Endocrinology, vol. 46, no. 10, pp. 4491-4499, 2005.

[63] C. Scorticati, J. Fernández-Solari, A. de Laurentiis et al., "The inhibitory effect of anandamide on luteinizing hormone-releasing hormone secretion is reversed by estrogen," Proceedings of the National Academy of Sciences of the United States of America, vol. 101, no. 32, pp. 11891-11896, 2004.

[64] L. di Matteo, M. Vallarino, and R. Pierantoni, "Localization of GnRH molecular forms in the brain, pituitary, and testis of the frog, Rana esculenta," Journal of Experimental Zoology, vol. 274, no. 1, pp. 33-40, 1996.

[65] R. Chianese, V. Ciaramella, S. Fasano, R. Pierantoni, and R. Meccariello, "Anandamide modulates the expression of GnRHII and GnRHRs in frog, Rana esculenta, diencephalon," General and Comparative Endocrinology, vol. 173, no. 3, pp. 389-395, 2011.

[66] R. Meccariello, R. Chianese, S. Fasano, and R. Pierantoni, "Endocannabinoids and kisspeptins: two modulators in fight 
for the regulation of GnRH activity," in Gonadotropins, J. Vizcarra, Ed., pp. 57-88, InTech, Rijeka, Croatia, 2013.

[67] R. Chianese, V. Ciaramella, S. Fasano, R. Pierantoni, and R. Meccariello, "Kisspeptin receptor, GPR54, as a candidate for the regulation of testicular activity in the frog Rana esculenta," Biology of Reproduction, vol. 88, no. 3, p. 73, 2013.

[68] P. Morales, E. Pizarro, M. Kong, and C. Pasten, "Sperm binding to the human zona pellucida and calcium influx in response to GnRH and progesterone," Andrologia, vol. 34, no. 5, pp. 301-307, 2002.

[69] R. Pierantoni, G. Cobellis, R. Meccariello et al., "Testicular gonadotropin-releasing hormone activity, progression of spermatogenesis, and sperm transport in vertebrates," Annals of the New York Academy of Sciences, vol. 1163, pp. 279-291, 2009.

[70] R. Yanagimachi, "Fertility of mammalian spermatozoa: its development and relativity," Zygote, vol. 2, no. 4, pp. 371-372, 1994.

[71] T. Shono and J. M. Hutson, "Capsaicin increases the frequency of cryptorchidism in flutamide-treated rats," Journal of Urology, vol. 152, no. 2, pp. 763-765, 1994.

[72] S. C. Mizrak, B. M. Gadella, H. Erdost, A. Ozer, A. M. M. van Pelt, and F. M. F. van Dissel-Emiliani, "Spermatogonial stem cell sensitivity to capsaicin: an in vitro study," Reproductive Biology and Endocrinology, vol. 14, no. 6, article 52, 2008.

[73] S. C. Mizrak and F. M. F. van Dissel-Emiliani, “Transient receptor potential vanilloid receptor-1 confers heat resistance to male germ cells," Fertility and Sterility, vol. 90, no. 4, pp. 1290-1293, 2008.

[74] T. Ilhan and H. Erdost, "Effects of capsaicin on testis ghrelin expression in mice," Biotechnic and Histochemistry, vol. 88, no. 1, pp. 10-18, 2012.

[75] G. Rossi, V. Gasperi, R. Paro, D. Barsacchi, S. Cecconi, and M. Maccarrone, "Follicle-stimulating hormone activates fatty acid amide hydrolase by protein kinase A and aromatase-dependent pathways in mouse primary sertoli cells," Endocrinology, vol. 148, no. 3, pp. 1431-1439, 2007.

[76] C. S. J. Walpole, S. Bevan, G. Bovermann et al., "The discovery of capsazepine, the first competitive antagonist of the sensory neuron excitants capsaicin and resiniferatoxin," Journal of Medicinal Chemistry, vol. 37, no. 13, pp. 1942-1954, 1994. 


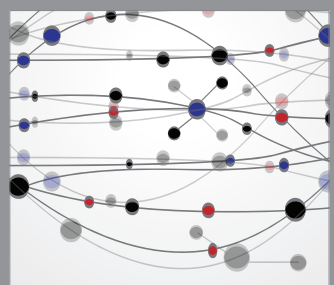

The Scientific World Journal
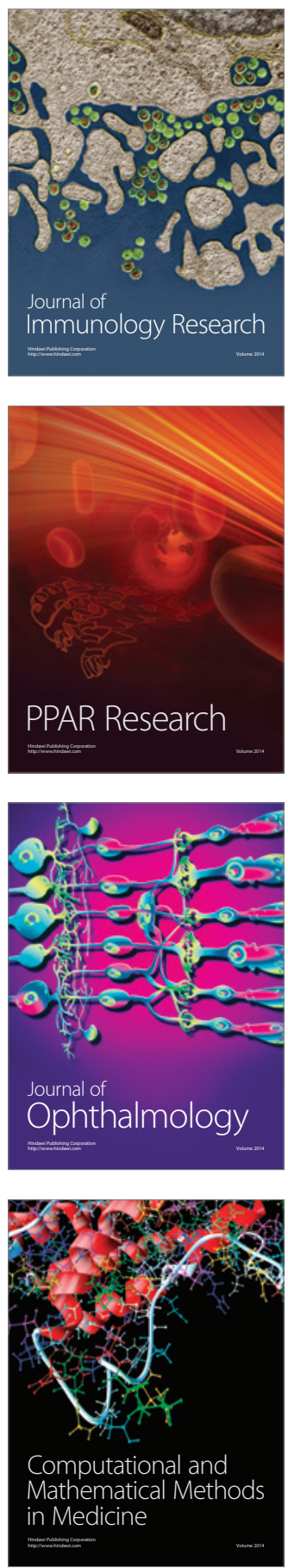

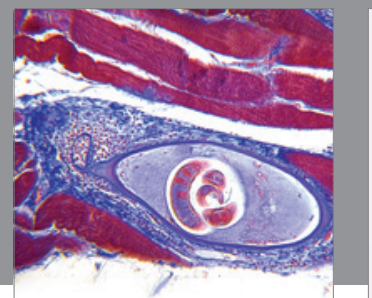

Gastroenterology

Research and Practice
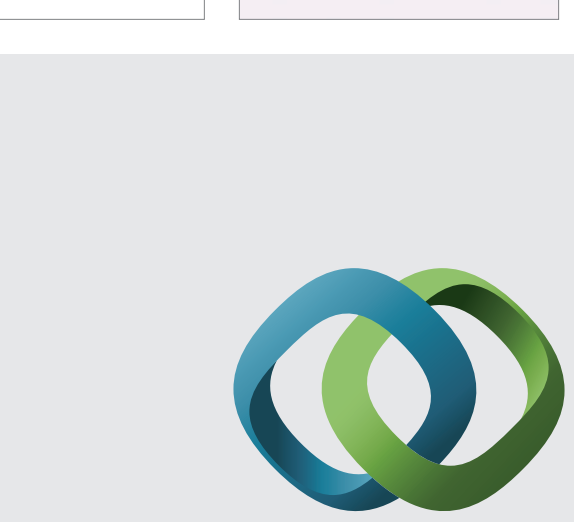

\section{Hindawi}

Submit your manuscripts at

http://www.hindawi.com
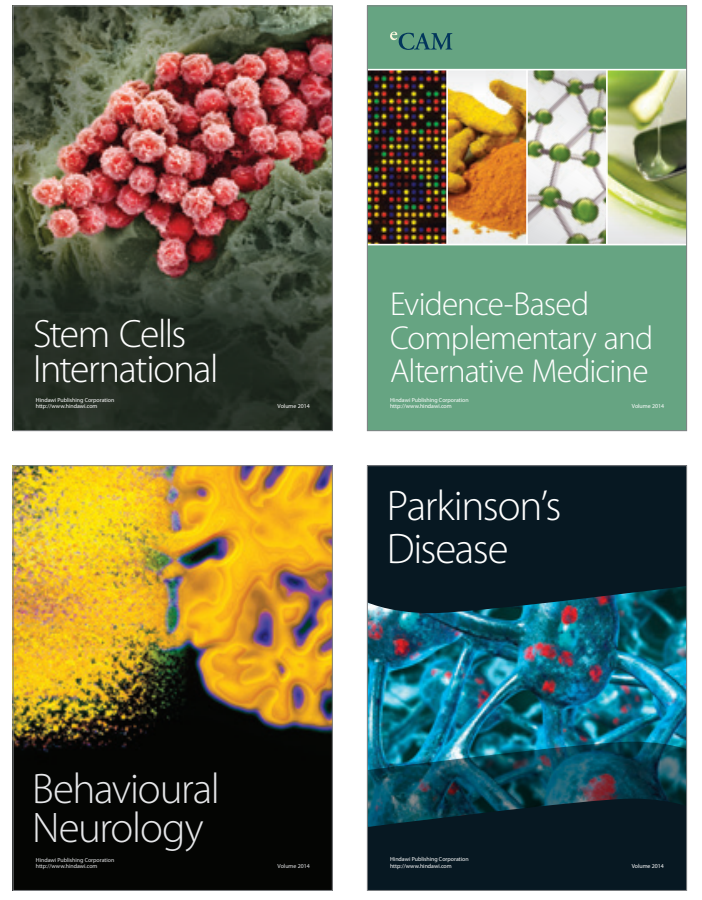
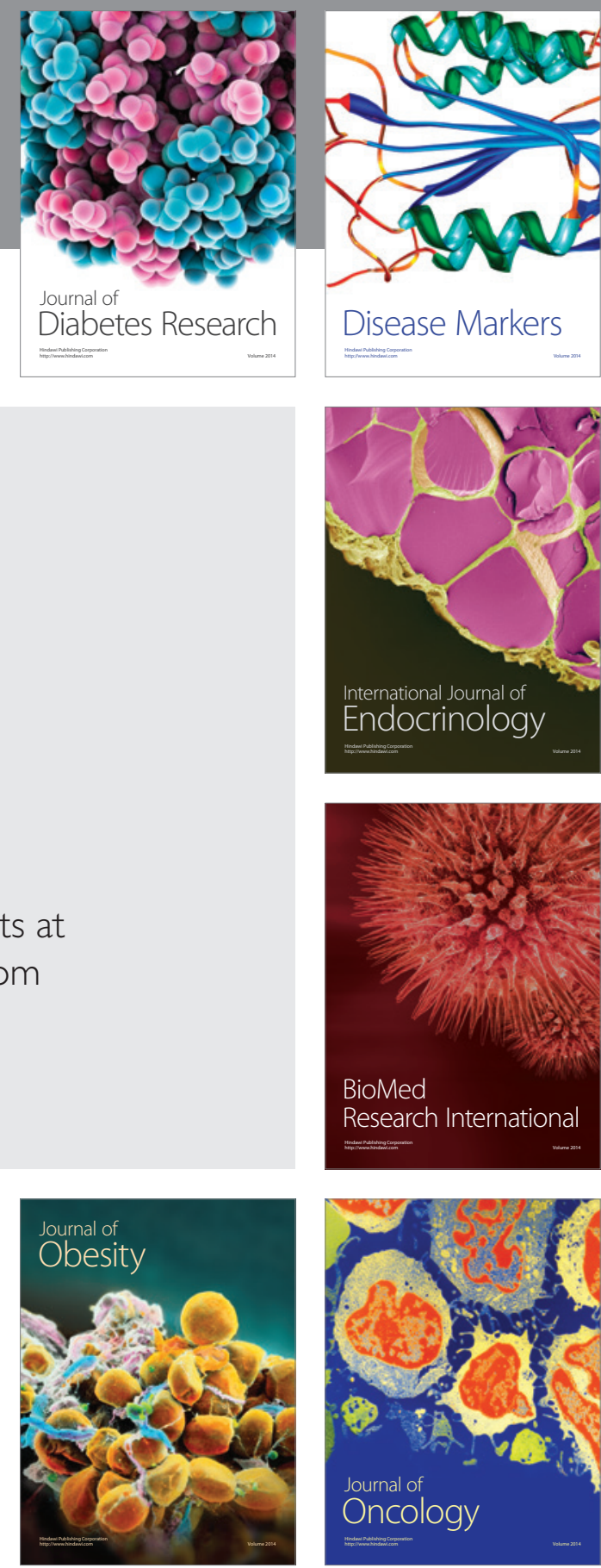

Disease Markers
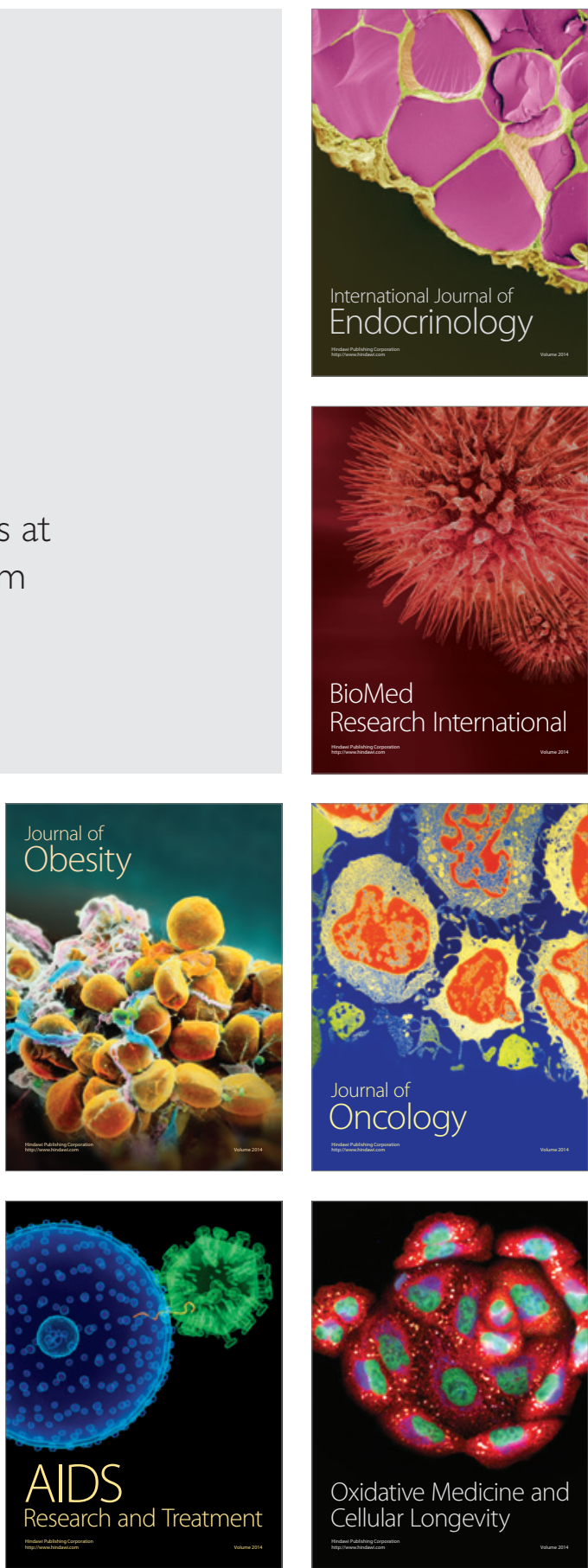